By HERBERT KLEIST

\title{
Inverse Time Order and Subject Filing
}

Mr. Kleist, formerly at John Crerar Library and now at Yale, submitted this paper early in 1944 on the basis of experience and observation at the former library.

$\mathrm{O}$ NE OF THE PROBLEMS of which libraries have always been acutely aware, as the literature of the profession eloquently testifies, is that posed by the barriers of one kind or another which separate the reader from the books he wants for his information or delectation. That a satisfactory solution has never been found is not surprising in view of the complexity of the problem, involving as it does both psychological and technical or mechanical factors. Paradoxically, but obviously, that tool which is commonly considered to be the "key" to the library's resources, ${ }^{1}$ namely, the catalog, is not without numerous peculiar pitfalls of its own for the unwary and uninitiated. Since every librarian is familiar with the vagaries of filing order and subject headings, these pitfalls need not be described here. Because of them, however, the catalog is not so much a key to the library's book collection as a door or lock, the real key to which is an exact and detailed knowledge of the filing arrangement and even, in the case of a classed catalog, of the classification scheme, since the alphabetical subject index to the classed catalog is not an infallible guide. Few outside of

1 Van Hoesen, Henry Bartlett, and Walter, Frank K. Bibliography, Practical, Enumerative, Historical. New York City, Scribner's, I928, p. 139. the profession, however, have such knowledge.

In a utopian frame of mind it is possible to imagine the library catalog of the future as having a supplement in the form of a list of subject headings in plain view, say on the walls surrounding the catalog, so that the reader could locate his subject in the same easy way in which he now finds a room number from the directory on the first floor of the modern skyscraper office building. This would enable him quickly to orientate himself among the great number of subjects.

It is further possible to imagine that, having found his subject in the list, he could go to a catalog containing trays of such a nature (perhaps extensible, with tough but flexible cards) that the cards could be manipulated so as to lie flat and expose to view just enough of each card in the tray to show the author and title, in the manner of the visible or Kardex file, thus eliminating the laborious thumbing of every card necessary at present. Visionary? To be sure. And quite impossible or at best impracticable? Perhaps-today. As for tomorrow, the answer must be left to our friends in the library equipment business. The problem is hereby discreetly placed in their collective lap.

The main purpose of introducing at this point the foregoing digression into utopia was to emphasize how far present library catalogs fall short of what they ideally 
should be: not doors which can be unlocked only with time-consuming laboriousness, but open windows, permitting a direct and immediate view of the record of the library's resources. In the absence of any such radical modifications each library must be content with whatever refinements are available and suitable to make the catalog more effective.

\section{Chronological Arrangement of Catalog Cards}

A distinctive feature of the John Crerar Library public catalog which its readers find very useful is the chronological arrangement of the cards in the alphabetical subject and the classed catalogs. (These are separate from the author catalog.) The cards are filed under each subject or class number, not in the usual alphabetical arrangement by author, but by date of publication, in inverse chronological order, so that the card for the latest book files in front. This enables the reader to see at once what is the most recent book on any particular subject, a matter of prime importance in a large library specializing in technology and the sciences.

The scheme is not a new one, having been adopted by J.C.L. when it was established in 1894. A decade earlier its use at Columbia College Library was described by W. S. Biscoe ${ }^{2}$ and its partial use in a library in Vienna was reported at about the same time. ${ }^{3}$ Mr. Biscoe, however, was chiefly interested in the application of the time order to books on open shelves rather than as an aid in searching the catalog. C. W. Andrews, first librarian of J.C.L., in urging a more widespread use of the scheme, also emphasized particularly its

\footnotetext{
${ }^{2}$ Biscoe, W. S. "Chronological Arrangement on Shelves." Library Journal ro:246-47, September-

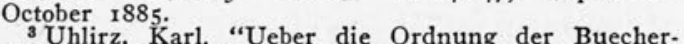
titel im Systematischen Kataloge." Zentralblatt für Bibliothekswesen $1: 461-67$, December 1884 .
}

usefulness for this purpose. ${ }^{4}$ While access to the stacks has lost little, if any, of its importance in college and university libraries, it now plays but a relatively minor role in a library such as J.C.L. It is, therefore, with the value of the time order in locating books through the catalog that the present article is concerned. It is written as the experience of one library and in the full realization that circumstances alter cases.

\section{Finding Latest Acquisitions}

Although W. S. Merrill discussed this subject a number of years ago, ${ }^{5}$ it is perhaps not amiss to call attention at least once in every decade to a scheme at once so simple and so useful. Moreover, Mr. Merrill was concerned primarily with answering objections which might be raised against it by proponents of the alphabetical arrangement and, for the rest, did not go beyond a statement of its value in showing quickly the latest acquisitions of a library under any subject.

This everyday function of the time order is of course its most obvious and most important one. If the latest book on, say, air power has been written by a man whose name begins with $Z$, the alphabetical arrangement places the card last under the subject, whereas the time order brings it to the front where the reader will see it first. Under the usual arrangement, if the reader is not familiar with authors writing in this field he might not reach the latest book until he had examined every card filed under the subject. If he had little time and less patience, as is unfortunately often the case, he would probably select a title before he had come to the

\footnotetext{
-Andrews, C. W. "Principles of Classification." A.L.A. Bulletin 11:195-97, July 1917 .

Merrill, William Stetson. "Order of Books by Date under Subjects." Library Quarterly 4:282-84, April 1934 .
} 
last card and would not be aware that a more recent one was available.

\section{Latest Bibliographies, Also}

On the other hand, from the standpoint of the reader who wishes to do more extensive research, the ability to get at once the latest books (even if the latest happen not to be the best) offers the further advantage that the bibliography which in all probability would be included in one of these would acquaint him not only with other important books in that or related fields but with the periodical literature as well. Thus he gains in two ways: he is spared the tedious search through the periodical indexes, which he now needs to consult only for the period subsequent to the date of his book, and he is the beneficiary of the "sifting" of the literature which the author has already carried out for him.

In addition to this everyday function, however, there are other situations in which the time order helps out immensely. A few examples will make this clear. A reader seeking the exact date when a certain improvement was first incorporated into the steam engine is unable to find any reference to it in the recent historical literature or in the comprehensive descriptive treatises. Since he knows the approximate date, it is a matter of a few seconds to examine the group of subject cards of books published about that time and to select a history of the steam engine, where the desired information may be found. Because improvements often lose their relative importance with the passage of time, recent books are not as likely to mention them as are the contemporary ones. An approach such as this is impossible with the alphabetical arrangement. Provided one existed, a bibliography might turn the trick since the arrangement is usually chronological, though it would not be as convenient as the catalog with the time order.

\section{“Catching Up" on Latest Publications}

Frequently also a reader will come in to "catch up" on his subject and will be interested only in the literature published within the last few years. The alphabetical arrangement necessitates his looking through all the cards filed under the subject, whereas the time order segregates the material chronologically, and the guide cards marking off every few years quickly show him how much material of interest to him is in the library. Similarly the literature published during any other period may quickly be examined if that is the approach the problem requires. For example, not infrequently short subject bibliographies of recent books based on the library's resources are prepared at the request of readers. This is a relatively simple matter if, instead of all the cards, only those of the last few years need be examined.

The time order further stands the library in good stead in the matter of the "weeding out" of books which have outlived their usefulness, already mentioned early in this century by an English librarian. ${ }^{6}$ Today it is a rash librarian indeed who will take it upon himself to discard this book or that one as of no further use to anyone. The problem is envisaged rather as one requiring the segregation of entire groups of books for storage elsewhere than on the shelves of the library proper. Here again the chronological order will save incalculable time if the segregation is made mainly on a chronological basis.

Two other advantages may be mentioned in conclusion. Mr. Andrews pointed out that the time order "provides a most convenient method of dividing scientific and technical books into those little used and those more used, in order to give the latter the most accessible shelves." ${ }^{7}$ Analogously,

- Stephen, G. A. "The Application of Exact Classification to Shelf Arrangement." Library World $11: 326$, March I9.09.

${ }_{7}$ Op. cit., p. 196. 
in the catalog this arrangement spares the older cards the unnecessary wear and tear which they receive under the alphabetical arrangement, since, in the main, readers will use only the more recent cards grouped in front. Finally, when the purchase of a book or the making of analytics of a set is being considered, the time order readily reveals the up-to-dateness of the library's resources in the field in question, a factor which may be decisive in determining whether the purchase or the analytics should be made.

\section{Disadvantages}

There are, of course, certain respects in which the time order shows at a disadvantage. Not infrequently a reader will request a book by an author with a very common name, such as Smith or Wood, first name unknown. If the catalog is full of Wood's, as it is sure to be, the subject approach may be a lifesaver if the arrangement is alphabetical, provided always that the subject is specific enough so that one will not have to search half a dozen subjects. The filing of the cards, too, requires a good deal of care. The corollary of the chronological arrangement is the use of time numbers as book numbers, but because of certain exceptions it is necessary to examine both the imprint date and the time number when filing.

These are minor disadvantages, however, which weigh very lightly in the balance in comparison with what the inverse time order tells by placing the latest card first.

\section{The Value of Russian to the Reference Librarian}

\section{(Continued from page 198)}

In closing we may summarize by saying that even at present a reference librarian with some knowledge of Russian is needed in any library where there are Russian books and there is every sign that the demand for such knowledge of Russian will greatly increase in the postwar years. 